\title{
Open Reduction by Fenestration to the Ilium for Central Acetabular Depression Fractures: A Case Report and Operative Technique
}

\author{
Kazushige Yoshida1, Masaaki Maruyama², Kentaro Kasama², Hiroyuki Hashidate², \\ Kazumi Kitagawa ${ }^{2}$ \\ ${ }^{1}$ Department of Orthopedic Surgery, Shinshu University Hospital, Matsumoto City, Japan \\ ${ }^{2}$ Department of Orthopedic Surgery, Shinonoi General Hospital, Nagano City, Japan \\ Email: kazuyoshi@shinshu-u.ac.jp,sgh_iizu@grn.janis.or.jp,eagle1111srixon@gmail.com, \\ hashidate4789@yahoo.co.jp,kitakazu_212@msn.com
}

Received 18 April 2016; accepted 17 July 2016; published 20 July 2016

Copyright (C) 2016 by authors and Scientific Research Publishing Inc.

This work is licensed under the Creative Commons Attribution International License (CC BY).

http://creativecommons.org/licenses/by/4.0/

(c) (i) Open Access

\begin{abstract}
Aim: The aim was to report a fenestration technique for gap reduction of acetabular depression fractures. Case presentation: A 76-year-old man suffered from severe left leg pain. The computed tomography scanning showed a displaced acetabular depression fracture, including a third fracture fragment in the center of the acetabular weight-bearing area. We performed a fenestration technique to fenestrate the outer plate of ilium to push down the dislocated fragment of the fracture. The patient was pain-free with good functional outcome of the hip joint at three years after operation. Conclusion: The fenestration technique is useful for displaced acetabular depression fractures. We performed open reduction in this particular case, but the technique may be done less invasively with the use of hip arthroscopy.
\end{abstract}

\section{Keywords}

Hip Fracture, Fenestration, Acetabular Fracture

\section{Introduction}

Acetabular fractures are often caused by indirect forces from the femur, and because the hip is a weight bearing joint, the aim for operative treatment is to perform a precise reduction and maintain a strong fixation. However, due to its anatomical characteristics and vicinity to important structures, there are many reports of complications that require advanced surgical techniques for treatment. We reported a case of an acetabular depression fracture 
in conjunction with a central fracture dislocation of the hip that was treated with fenestration. We believe that this is an easy, safe, and unique surgical technique to reduce depression fractures in the central area of the joint. To our knowledge, there are no reports describing the use and clinical results of fenestration for this relatively rare fracture type.

\section{Informed Consent}

The patient was given informed consent to participate in this clinical study, and our hospital IRB (Institutional Review Board) approval has been obtained for the study.

\section{Case Report}

A 76-year-old man suffered a left acetabular fracture and was transported to our hospital by ambulance due to a walking disability with severe left hip joint pain. It was unknown how he was injured, except that he slipped and fell from the third step of a stepladder. Despite having right mild hemiplegia caused by cerebral infarction that had occurred 3 years earlier, he required no crutches for his ambulation prior to injury. The patient presented no acute neurological change and had hypertension managed in the emergency room.

The acetabular fracture was not apparent on the initial radiographs, including the anteroposterior and oblique views of the pelvis; however, CT scanning presented a fracture of the ilium, a displaced acetabular depression fracture with third fragments in the center of the weight-bearing area, and a central dislocation of the hip with spontaneous reposition (Figure 1, Figure 2). The fracture line extended anteromedially from the acetabulum, and the proximal fragment was positioned between the anterior superior and anterior inferior iliac spine, though there was no evidence of fracture lines on the outer table of the ilium. An ischial ramus fracture was confirmed, and the fracture was diagnosed as an incomplete acetabular fracture of the anterior column (AO 62. A3); alternatively, the fracture type could also be interpreted as a combined fracture of the ischial ramus and anterior column. The depressed fragment of the articular surface was displaced approximately $8.5 \mathrm{~mm}$.

Because the displacement of the fracture was minimal and demonstrated continuity with the outer table, the patient underwent surgery in order to maintain congruity of the articular surface. The common classification reported by Judet \& Letournel [1] in 1964 was not suitable for this case, as the fracture fragments created an incongruity of the acetabular articular surface and the potential for hip joint instability. Therefore, the patient was treated with open reduction and internal fixation.

\subsection{Surgical Technique}

The patient was placed in the lateral decubitus position and stabilized on a sir-fluidized body fixation system

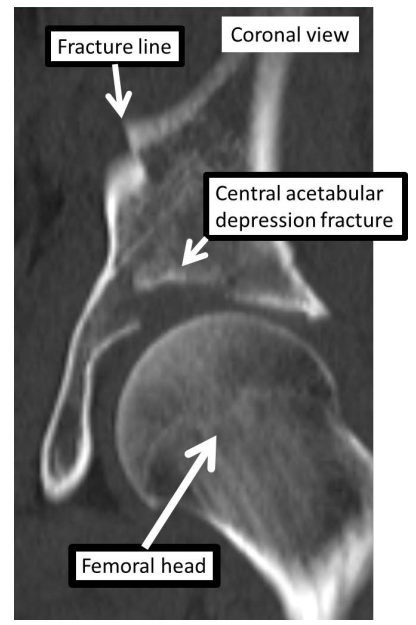

Figure 1. Two-dimensional coronal plane CT scan of the central acetabular depression fracture. 


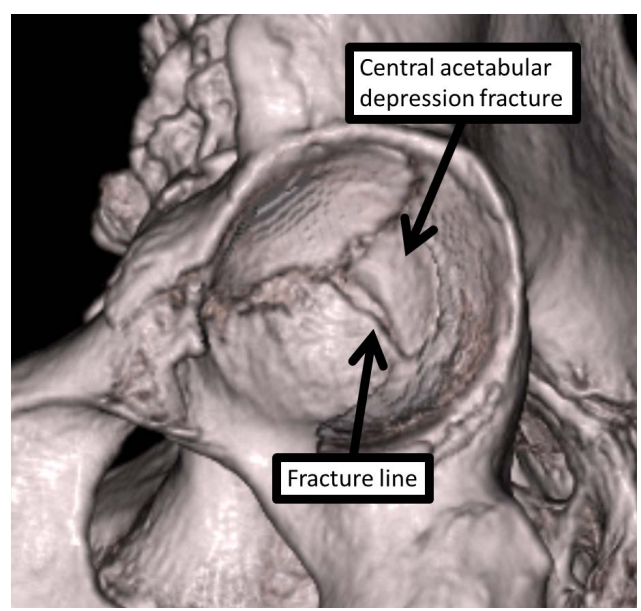

Figure 2. Three-dimensional CT imaging of the central acetabular depression fracture.

(Magic Bed ${ }^{\mathrm{TM}}$, Nikko Fines Industries Co. Ltd., Tokyo, Japan [identical to the Vac-Pac ${ }^{\mathrm{TM}}$ Surgical Positioning System; Olympic Medical Co. Ltd., Seattle, WA, USA]). A direct lateral incision to the hip was used for exposure. The skin incision began distally in the anterodistal border of the greater trochanter and extended proximally via a curved line over the trochanter, tracing the lines of the gluteus maximus muscle fiber. The total length of the skin incision was $17 \mathrm{~cm}$. The fascia latae was incised in the same configuration as the skin incision. The gluteus maximus was split along the muscle fiber. The anterior inferior iliac spine was identified via the anterior border of the gluteus medius muscle. It was unnecessary to incise the superficial aponeurosis of the tensor fasciae latae, which was left intact to protect the lateral cutaneous femoral nerve during surgery. The short rotator muscles and their tendons were identified, and the piriformis tendon was released. Along the piriform recess, a curved Kocher clamp was passed behind the gluteus minimus and capsule of the hip joint, and a Gigli wire saw was drawn back using this clamp. The vastus lateralis was released $1 \mathrm{~cm}$ distally from its origin, a trochanteric osteotomy was performed by saw from the piriform recess to the releasing point, and the gluteus minimus muscle was detached from the capsule of the hip by a blunt dissection to reflect the greater trochanter, gaining access to the joint space and acetabular rim.

To observe the articular surface and identify the fracture fragment, the femoral head was posteriorly dislocated with excision of the teres ligamentum after a T-shaped capsulotomy. At this time, caution should be paid to prevent damage to the medial circumflex femoral artery. The depressed fragment in the acetabulum was identified under gross observation but could not be repositioned intra-articularly. Consequently, the outer cortex of the ilium was fenestrated $2 \times 2 \mathrm{~cm}$ by a chisel so that a 1-cm-wide elevator could be inserted to the depressed fragment $1 \mathrm{~cm}$ proximally from the articular surface through the fenestrated window (Figure 3(a)). Subsequently, the displaced bone fragment was pushed down by using the elevator to the adequate articular joint level. The conceptual diagram of the reduction is shown as Figure 3(b). The fragment was stabilized with packed cancellous bone graft that was harvested from the osteotomized greater trochanter. The outer cortex of the ilium from the fenestrated site was removed, repositioned, and fixed by the harvested graft and a reconstruction plate.

After irrigation of the operative field, the dislocated femoral head was reduced. The hip joint capsule and the piriformis tendon were repaired with absorbable sutures. The osteotomized greater trochanter was reattached and fixed with two $6.5 \mathrm{~mm}$ cannulated cancellous hip screws. Layered closure was performed to repair the vastus lateralis, the fascia latae, subcutaneous and skin. There were no intraoperative complications.

\subsection{Postoperative Management}

During the hospital stay, toe-touch weight bearing, passive motion of the hip joint, and muscle-strengthening exercises with the exception of the abductor muscles were allowed within four days postoperatively. Partial weight bearing was started at 3 weeks and weight bearing as tolerated at 6 weeks. At 8 weeks, the patient was ambulating with one crutch. Deep venous thrombosis prophylaxis was prescribed for four weeks postoperatively. 


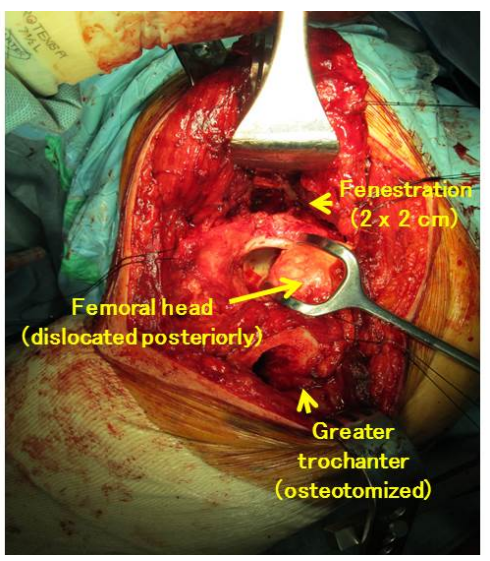

(a)

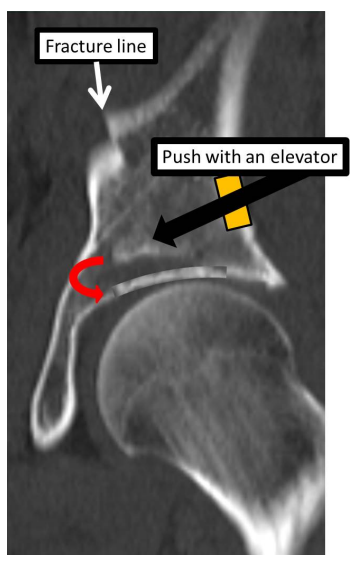

(b)

Figure 3. (a) Intraoperative findings of the central acetabular depression fracture. (b) The conceptual diagram of the intraoperative reduction

At 9-month follow-up, the acetabular depression fracture was completely reduced and healed in the CT scanning evaluation (Figure 4). At 3-year follow-up, the patient was pain-free and continued to function well without the use of external supports. Excellent functional results were observed in the case according to the Japanese Orthopedic Association Score [2] and Merle d'Aubigné Score [3] (95 out of 100 and 17 out of 18 points, respectively). There was no sign of post-traumatic osteoarthritis of the hip joint in radiographs 3-year postoperatively (Figure 5).

\section{Discussion}

In acetabular fracture dislocations of the hip joint, the precise pathological anatomy is not easily demonstrated by routine radiographs. The most commonly used classification for acetabular fractures has been based on conventional radiographs. There are some reports that the relationship among hardware, bones, and bone fragments are well demonstrated by using CT [4] [5]. In our case, however, details of the acetabular fracture were not well visible on conventional radiographs. It has been shown that CT is a useful technique in the precise evaluation of fracture type, bone damage, and integrity of joint configuration.

There is controversy over how large the gap in the articular surface is permissible. Some authors have mentioned that the border line of the gap may be within $2 \mathrm{~mm}$ [6]. On the other hand, another report suggests that a residual gap over $1 \mathrm{~mm}$ after operation had a higher risk of osteoarthritis than a group within $1 \mathrm{~mm}$ [7]. We believe that the gap should be minimized as much as possible in order to prevent post-traumatic osteoarthritis.

Brumback et al. [8] reported an acetabular depression fracture accompanying a posterior fracture dislocation of the hip, and Ganz et al. proposed an approach to avoid potential risks to the vascularity while maintaining the external rotator muscles and medial femoral circumflex artery to avoid avascular necrosis of the femoral head. Although the technique described by Ganz is now widely used for acetabular fractures of the hip, the surgical exposure is not adequate enough superiorly to fenestrate the outer table of the ilium due to its vulnerability to muscular tightness. In our case, the fracture fragment existed in the center of the weight bearing area of the acetabulum and could neither be reduced nor fixed by intra-articular management alone. Thus, we needed to divide the external rotator muscles to expose the outer table of the ilium and perform fenestration on the intact bony cortex of the ilium, just proximal to the fracture site. To our knowledge, there are no reports describing our fenestration technique; however, we believe our technique is useful for obtaining a good reduction for central acetabular depression fractures.

There is a potential need for a simple and precise approach for central acetabular fractures of the hip joint. The approaches and surgical techniques previously reported for the pelvic fracture [1] had an advantage for extra-articular or combined intra- and extra-articular fracture reduction. However, these techniques provided no solution for the treatment of an isolated intra-articular depression fracture. Thus, we performed this operation using a new technique that was specialized for reduction and fixation for the intra-articular fracture of the acetabulum. In order to intra-articularly evaluate the reduction of a fracture fragment, hip endoscopy with a short 


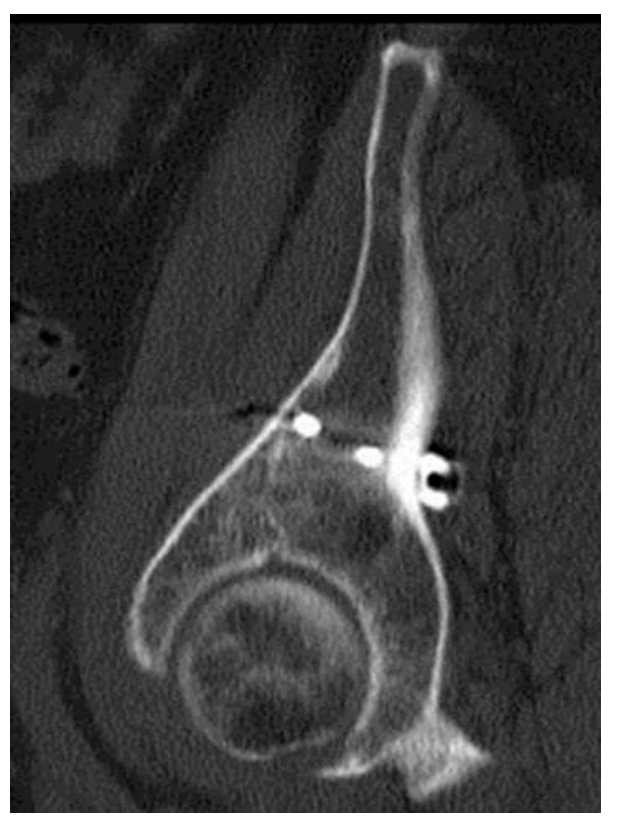

Figure 4. Two-dimensional sagittal plane CT scan of the reduced central acetabular depression fracture at 9 months after operation.

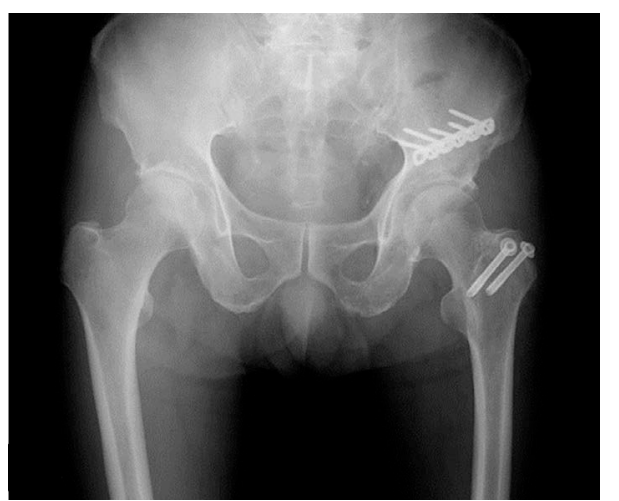

Figure 5. Signs of posttraumatic osteoarthritis of the hip joint were not present in radiographs at three years after operation.

incision, fenestration to the outer cortex of the ilium, and reduction by a bone tamp similar to those used in the treatment of tibial plateau fractures may provide a less invasive treatment [9].

In spite of a precise anatomic reduction of the acetabular fracture and good results at three years after operation, long-term follow-up of this case is still required, because a significant degenerative change of the affected hip joint may be expected.

\section{Conclusion}

The fenestration technique is useful for displaced acetabular depression fractures. Although we performed an open reduction in this particular case, the technique might be done less invasively with the use of hip arthroscopy, similar to the use of knee arthroscopy in tibial plateau fractures.

\section{References}

[1] Judet, R., Judet, J. and Letournel, E. (1964) Fractures of the Acetabulum: Classification and Surgical Approaches for 
Open Reduction. Preliminary Report. Journal of Bone and Joint Surgery-American, 46, 1615-1646.

[2] Hasegawa, Y., Iwata, H., Mizuno, M., Genda, E., Sato, S. and Miura, T. (1992) The Natural Course of Osteoarthritis of the Hip Due to Subluxation or Acetabular Dysplasia. Archives of Orthopaedic and Trauma Surgery, 111, 187-191. http://dx.doi.org/10.1007/BF00571474

[3] Merle D’Aubigne, R. (1953) [Functional Results of Arthroplasty of the Hip]. Acta Orthopaedica Belgica, 19, 81-103.

[4] Senohradski, K., Karovic, B. and Miric, D. (2001) [Computer Tomography in the Diagnosis and Therapy of Acetabular Fractures]. Srp Arh Celok Lek, 129, 194-198.

[5] Falchi, M. and Rollandi, G.A. (2004) CT of Pelvic Fractures. European Journal of Radiology 50, 96-105. http://dx.doi.org/10.1016/j.ejrad.2003.11.019

[6] Giannoudis, P.V., Grotz, M.R., Papakostidis, C. and Dinopoulos, H. (2005) Operative Treatment of Displaced Fractures of the Acetabulum. A Meta-Analysis. Journal of Bone and Joint Surgery-British, 87, 2-9.

[7] Matta, J.M. (1996) Fractures of the Acetabulum: Accuracy of Reduction and Clinical Results in Patients Managed Operatively within Three Weeks after the Injury. Journal of Bone and Joint Surgery-American, 78, 1632-1645.

[8] Brumback, R.J., Holt, E.S., McBride, M.S., Poka, A., Bathon, G.H. and Burgess, A.R. (1990) Acetabular Depression Fracture Accompanying Posterior Fracture Dislocation of the Hip. Journal of Orthopaedic Trauma, 4, 42-48. http://dx.doi.org/10.1097/00005131-199003000-00008

[9] Holzach, P., Matter, P. and Minter J. (1994) Arthroscopically Assisted Treatment of Lateral Tibial Plateau Fractures in Skiers: Use of a Cannulated Reduction System. Journal of Orthopaedic Trauma, 8, 273-281.

http://dx.doi.org/10.1097/00005131-199408000-00001

\section{Submit or recommend next manuscript to SCIRP and we will provide best service for you:}

Accepting pre-submission inquiries through Email, Facebook, LinkedIn, Twitter, etc.

A wide selection of journals (inclusive of 9 subjects, more than 200 journals)

Providing 24-hour high-quality service

User-friendly online submission system

Fair and swift peer-review system

Efficient typesetting and proofreading procedure

Display of the result of downloads and visits, as well as the number of cited articles

Maximum dissemination of your research work

Submit your manuscript at: http://papersubmission.scirp.org/ 